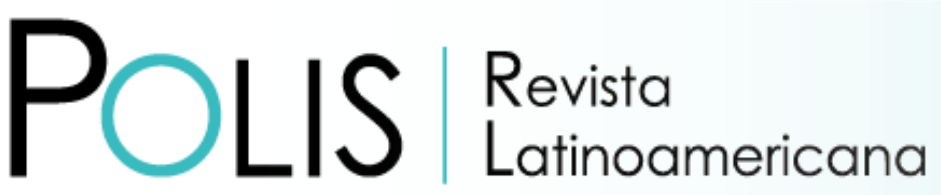

V20 | N59 | 2021

DOI:10.32735/S0718-6568/2021-N59-1590

\title{
¡Nunca más solas! Acoso sexual, tsunami feminista, y nuevas coaliciones dentro y fuera de las universidades chilenas
}

\author{
Hillary Hiner \\ Universidad Diego Portales, Santiago, Chile \\ Email: hillary.hiner@udp.cl \\ Ana López Dietz \\ Universidad Central de Chile, Santiago, Chile \\ Email: analopezdietz@gmail.com
}

Recibido: 30.10 .2020

Aceptado: 18.03.2021

\begin{abstract}
Resumen: Durante los últimos cuarenta años ha habido una cantidad no menor de estudios sobre acoso sexual en las universidades del Norte Global. No obstante, hay relativamente poco sobre el acoso sexual dentro de universidades latinoamericanas. Este artículo explora el caso chileno, adonde, desde el 2015 en adelante existe una cantidad cada vez más grande de denuncias por acoso sexual en las universidades. Como resultado, en el año 2018 aconteció el "Tsunami Feminista", liderado por estudiantes feministas. En este artículo ocuparemos fuentes de prensa, entrevistas y grupos de discusión hechos con estudiantes y activistas feministas, para analizar el Tsunami Feminista y el acoso sexual en las universidades. A la misma vez, también exploraremos algunas de las resistencias desarrolladas por estudiantes, académicas y profesionales feministas dentro y fuera de las universidades, a la hora de plantear estrategias y coaliciones anti-acoso. Nuestra hipótesis plantea que fue justamente la emergencia de coaliciones y redes diversas, entre estudiantes, académicas, y profesionales feministas, que asentó las bases para una denuncia potente anti-acoso dentro de las universidades y un frente feminista intergeneracional fuerte en torno esta temática, poco trabajada hasta ese momento.
\end{abstract}

Palabras clave: Acoso sexual; coaliciones y redes; movimiento feminista; universidad; Chile.

\section{Not Alone Anymore! Sexual Harassment, Feminist Tsunami, and New Coalitions in Chilean Universities}

\begin{abstract}
During the last forty years there has been a fairly large body of research focused on sexual harassment in Global North universities. At the same time, there is relatively little on sexual harassment in Latin American universities. This article explores the Chilean case, where, from 2015 to the present, there have been an ever-increasing number of sexual harassment complaints at universities. As a result, in 2018 the Feminist Tsunami occurred, led by feminist students. In this article we will use press sources, interviews and discussions groups with students and feminist activists in order to analyze the Feminist Tsunami and sexual harassment at universities. At the same time, we will also explore some of the
\end{abstract}


resistances developed by feminist students, academics and professionals, inside and outside of universities, when thinking about anti-harassment strategies and coalitions. Our hypothesis is that it was the emergence of diverse coalitions and networks, between feminist students, academics and professionals that allowed for the emergence of a very strong anti-harassment position at universities, as well as a powerful intergenerational feminist front to combat sexual harassment, a relatively invisible type of violence up until that moment.

Keywords: Sexual harassment; coalitions and networks; feminist movement; university; Chile.

\section{Nunca mais sozinhas! Assédio sexual, tsunami feminista e novas coalizões dentro das universidades chilenas}

Resumo: Durante os últimos quarenta anos, tem havido um grande número de pesquisas focadas no assédio sexual nas universidades do Norte Global. Ao mesmo tempo, há relativamente pouco sobre assédio sexual nas universidades latino-americanas. Este artigo explora o caso chileno, onde, de 2015 até o presente, houve um número cada vez maior de reclamações de assédio sexual em universidades. Como resultado, em 2018, ocorreu o "Tsunami Feminista", liderado por estudantes feministas. Neste artigo usaremos fontes da imprensa, entrevistas e grupos de discussão realizados com estudantes e ativistas feministas, bem como analisaremos o Tsunami Feminista e o assédio sexual nas universidades. Ao mesmo tempo, também exploraremos algumas das resistências desenvolvidas por estudantes, acadêmicas e profissionais feministas dentro e fora das universidades, quando se trata de propor estratégias e coalizões anti-assédio. Nossa hipótese propõe que foi precisamente o surgimento de diversas coalizões e redes, entre estudantes feministas, acadêmicas e profissionais, que lançou as bases para uma poderosa reclamação contra o assédio dentro das universidades e uma forte frente feminista intergeracional em torno do assunto, pouco elaborada até aquele momento.

Palavras-chave: Assédio sexual; coalizões e redes; movimento feminista; universidade; Chile.

\section{Como citar este artículo:}

Hiner, H. y López Dietz,A. (2021). ¡Nunca más solas! Acoso sexual, tsunami feminista, y nuevas coaliciones dentro y fuera de las universidades chilenas. Polis Revista Latinoamericana, 20 (59), 122-146. doi: http://dx.doi.org/10.32735/S0718-6568/2021-N59-1590

\section{Introducción}

El término "acoso sexual" (o sexual harassment, en inglés) emergió primero en el contexto del Norte Global y la re-activación del movimiento feminista durante los años 60 y 70 allá. En ese contexto, fue la feminista radical Catherine Mackinnon quien impulsó, a través de sus estudios y trabajos legales de abogada, definiciones y regulaciones en cuanto el acoso sexual, basadas en las desigualdades de los sexos en el trabajo y la violencia patriarcal (1979). Así, en 1980, la Comisión para la Igualdad de Oportunidades en el Empleo (Equal Employment Opportunity Comission, EEOC) de Estados Unidos, definió el acoso sexual de dos maneras: (1) quid pro quo, cuando se trata de favorecer o castigar a base de una peti-

ción sexual y (2) ámbito hostil, esto es: "conducta sexual que interfiere más allá de lo normal 
en la capacidad de trabajo de una persona o que crea un 'ámbito laboral intimidante, hostil u ofensivo'" (Kihnley, 2000, p. 70). Como numerosos estudios han demostrado (Benson y Thomson, 1982; Bogart y Stein, 1987), preocupación sobre acoso sexual en los ámbitos educacionales, y, en particular, universitarios, ya se había manifestado, en el caso de EEUU, a través del Título VII del Civil Rights Act de 1964, que prohíbe discriminación a base de raza, sexo, religión o nacionalidad, y el Título IX del Education Amendments Act de 1972, lo cual prohíbe explícitamente la discriminación a base de sexo dentro de programas educaciones que recibieran financiamiento estatal.

Como la mayoría de los estudios sobre acoso sexual en las universidades estadounidenses durante los años 80 y 90 demuestran, en primera instancia el enfoque principal tenía que ver con definir y visibilizar el acoso sexual dentro de las universidades, como también denunciar cómo el acoso sexual estaba dañando a las mujeres en esos contextos, en particular mujeres estudiantes de pre y post-grado (Bogart y Stein, 1987; Crocker, 1983; Dziech y Weiner, 1984; Kelley y Parsons, 2000). Para el siglo XXI, no obstante, también ha habido cada vez más reflexión en torno a cómo han funcionado, de forma "real", las normas internas de las universidades, las leyes y las desigualdades dentro de las universidades, ahora, más que nunca, desde perspectivas feministas interseccionales que también incluyeran preguntas sobre raza/etnicidad, clase, identidad de género y orientación sexual, entre otras variables (Chi Cantalupo y Kidder, 2017; Kihnley, 2000; Uggen y Blackstone, 2004). Esto se ha aumentado con particular fuerza en la última década, con discusiones más fuertes a base de casos conocidos de violación en los campus universitarios y de denuncias mediáticas de alto impacto sobre acoso sexual, relacionadas con movimientos sociales como \#MeToo y \#TimesUp. A la misma vez, a partir de los años 2000, ha habido un número cada vez mayor de estudios sobre acoso sexual en universidades en otras partes del mundo, y no sólo EEUU, apuntando hacia la seriedad y la prevalencia del acoso sexual en las universidades a nivel global (Jelil Ladebo, 2003; Vohlidalova, 2011).

En el caso de Chile, a diferencia de los protocolos y procedimientos ya establecidos y operando en la mayoría de las universidades norteamericanas y europeas a partir de los años 80, no existió casi ningún reconocimiento "oficial" del acoso sexual dentro de las universidades hasta hace pocos años (Zapata, 2016). Esto se empieza a derrumbar en octubre 2015 cuando una estudiante denunció a Fernando Ramírez, entonces profesor del Departamento de Ciencias Históricas de la Universidad de Chile, por acoso y abuso de poder, abriendo un sumario que terminó con el desvinculamiento del docente (Yañez y Salazar, 2016). En este marco, las estudiantes empezaron a organizar asambleas, foros y funas en torno al acoso sexual llevado a cabo por profesores dentro de la facultad. Desde ese momento en adelante, el movimiento feminista estudiantil en torno a la violencia sexual dentro de las universidades no se detuvo, extendiéndose a prácticamente todas las universidades públicas y privadas de Chile. El momento más álgido del movimiento se encuentra entre mayo y agosto 2018, el llamado "Mayo Feminista" o "Tsunami Feminista", cuando asambleas y organizaciones estudiantiles feministas 
hicieron paros extendidos y tomas en sus universidades, salieron a la calle masivamente y pidieron a gritos, y frecuentemente, en los medios masivos, la necesidad de contar con protocolos adecuados para enfrentar el acoso sexual dentro de las universidades.

Al mismo tiempo, y en conjunto con esta efervescencia de movilización feminista estudiantil, también comenzaron a organizarse, tal vez de manera algo más lenta y gradual, las académicas y profesionales feministas. En algunas universidades, en particular las públicas y las privadas más antiguas, el "Mayo Feminista" también involucró a otros estamentos, más allá de lo estudiantil, y apuntaba sus esfuerzos organizacionales, en particular, hacia las académicas, las administrativas y las auxiliares. Surgieron todo tipo de asambleas, comités y consejos, organizado en torno a temáticas como el acoso sexual, la educación no sexista y la brecha de género dentro de las universidades. En este contexto del año 2015 en adelante, también nacen nuevas organizaciones profesionales feministas, tales como la Red de Investigadoras (Redl, 2016) y la Red de Historiadoras Feministas (RHF, 2017), y la Red Docente Feminista (Redofem, 2018) y la Asociación de Abogadas Feministas (Abofem, 2019), entre otras.

En este artículo vamos a explorar como el Tsunami Feminista del año 2018 ha impactado por sobre el movimiento feminista y las universidades en Chile, desde una perspectiva feminista interseccional. Sin pretender abarcar todos los aspectos de este argumento, nos queremos concentrar en un elemento particular de este fenómeno, esto es cómo el Tsunami Feminista promovió la creación y consolidación de mayores coaliciones y redes entre feministas de diverso tipo, nivel y tamaño. Nuestra hipótesis plantea que fue justamente la emergencia de estas coaliciones y redes densas y diversas -entre/con estudiantes, académicas, estamentos universitarios, profesionales feministas, etc.- que fortaleció el movimiento en contra de la violencia/el acoso sexual dentro de las universidades y promovió la creación de un frente feminista intergeneracional fuerte en torno esta temática, poco trabajada hasta ese momento.

\section{Estudios sobre el movimiento feminista estudiantil}

El movimiento estudiantil chileno re-emergió con fuerza a partir de la "Revolución Pingüina", protagonizada por estudiantes secundarios/as en el año 2006, ampliándose aún más con la participación de estudiantes universitario/as en el año 2011, en el proceso de lucha contra la educación de mercado. No obstante, y como la bibliografía ha demostrado, los principales referentes o figuras del movimiento, y las organizaciones que lo conducían (centros de estudiantes, Federaciones y Confederaciones) tardaron en reconocer e incorporar temáticas de género y sexualidades a la hora de proponer la demanda por una educación pública, gratuita y de calidad (Mayol, 2012; Badilla, 2019; Cárdenas y Navarro, 2013; Paredes, 2019). Por otra parte, y como teóricas feministas como Alejandra Castillo (2016), Luna Follegati $(2016$, 2018), y Nelly Richard (2018) han analizado, críticas anti-neoliberales y disensos sobre la "democracia de los acuerdos" de los gobiernos de la Concertación también abundaban en ciertos sectores feministas y de disidencias sexuales, 
lo cual los hacía particularmente atractivos para estudiantes feministas y LGBTQ+ dentro de las universidades. A partir del año 2014, con la realización del primer Congreso de Educación No-Sexista y la formación de la Coordinadora Feministas en Lucha, temáticas como el aborto libre y la educación no sexista empezaban a aglutinar feministas dentro y fuera de las universidades, señalando un recambio generacional importante para el movimiento feminista en Chile (Follegati, 2018; Hiner y Vivaldi, 2019). A la misma vez, existen publicaciones recientes que destacan las desigualdades de género al interior de la academia, especialmente en cuanto la universidad neoliberal (Robert, Pitzer y Muñoz-García, 2018) y la precarización de las académicas mujeres (Duarte y Rodríguez, 2019; Fardella, 2020).

Algunos trabajos cronológicos recogen los principales hitos de movimiento (Paredes, Araya y Ortiz, 2019), mientras otras se enfocan en cómo, cuándo y por qué las estudiantes feministas denunciaron el acoso sexual dentro de las universidades y cuáles son los resultados para el movimiento feminista y las universidades en Chile (De Fina y Figueroa, 2019; Lillo, 2020; Reyes-Housholder y Roque, 2019; Zerán, 2018). Existe una línea de publicaciones que analizan las organizaciones estudiantiles feministas en regiones (Huenulef y Vargas, 2020; Alfaro y de Armas, 2019), como también una línea de estudios más críticos en cuanto la "educación no sexista" y el movimiento feminista estudiantil. Estas publicaciones (Troncoso et. al, 2019; Hiner y Troncoso, en prensa), preguntan no sólo por las metodologías y pedagogías feministas, sino también sobre las estrategias de movilización feminista estudiantil, tales como las "tomas de mujeres" o "tomas feministas". Finalmente, y allá del mundo de las publicaciones en revistas científicas, no es casual que algunos de los textos publicados en los últimos años provengan de organizaciones sociales que se relacionan con el movimiento feminista y estudiantil, como de la Red Chilena contra la Violencia hacia las Mujeres (2016) y el Colegio de Profesores (Acuña y Montecino, 2018).

\section{Teoría feminista sobre acoso sexual, protocolos y coaliciones}

Como ya mencionamos al abrir este artículo, hasta los años 70, en general, no se hablaba de "acoso sexual" - Mackinnon famosamente decía que estaba tan presente que se transformó en casi invisible (Uggen y Blackstone, 2004, p. 64) - y tampoco se problematizaba su existencia en el sistema educacional. Esto cambió con el activismo del movimiento feminista, como también a través de cambios legales y normas internas dentro de las universidades. Ya mencionamos como la EEOC codificaba el "acoso sexual" según dos definiciones - "quid pro quo" y "ámbito hostil" - y estas definiciones fueron ratificadas en lo legal por el caso de Meritor Savings Bank v. Vinson, un fallo de la Corte Suprema de 1986 (Kihnley, 2000, p. 70). Re-pensar el acoso sexual desde los campus universitarios fue particularmente importante por la enorme cantidad de mujeres que entraron a las universidades durante los años 60 y 70, llegando a ser la mitad o más de la población estudiantil. No obstante, los hombres dominaban en términos de poder y prestigio: para fines de los 70, 95\% de los profesores titulares eran hombres (Benson y Thomson, 1982, p. 239). 
Para los años 80 también se empezó a analizar, específicamente, cómo el acoso sexual se daba en las universidades. Según diferentes estudios de ese período, entre $13 \%$ y $49 \%$ de las mujeres estudiantes o empleadas de las universidades habían sido acosadas por académicos hombres; 0 , de 6 millones de mujeres que entraban a estudiar al año, aproximadamente 1 millón de ellas iban a vivir algún tipo de acoso antes de graduarse (Bogart y Stein, 1987, p. 149). La variación bastante grande en términos de porcentajes (entre 13 y 49\%) tenía que ver con factores entrelazados que se repetían entre estudios, tales como la dificultad de que las mujeres reconocieran, nombraran y denunciaran acoso sexual en las universidades, como también ciertos desafíos más metodológicos de las estudios a la hora de definir, recopilar y codificar instancias de acoso sexual (Welsh, 1999; Williams, Lam y Shively, 1992; Uggen y Blackstone, 2004). No obstante, estudios más recientes también han estimado figuras similares: entre $20-40 \%$ de estudiantes de pre y postgrado mujeres viven algún tipo de acoso sexual en la universidad y entre 40-50\% de mujeres académicas han vivido algún tipo de acoso sexual a lo largo de sus vidas académicas (Kelley y Parsons, 2000, p. 549).

En 1976, estudiantes de la Universidad de Yale ocuparon Título IX para querellarse en contra de su universidad, por no parar la discriminación a base de sexo; hasta el día de hoy se ocupa el Título IX como una de las principales herramientas a la hora de identificar el acoso sexual dentro de las universidades, como también para querellarse contra universidades que no cumplen con aspectos de esta ley, tales como no remover profesores acosadores y/o no educar sobre acoso sexual a nivel institucional y prevenir su ocurrencia (Kelley y Parsons 2000, p. 548-549). Desde el año 1990 en adelante, se ha aumentado, lo cual se ve de variadas maneras: el surgimiento de protocolos y normas internas sobre acoso sexual en las universidades, la apertura de oficinas de Título IX, centros de la mujer, y otros recursos dentro de las universidades, que iban a atender, directamente, a casos de acoso sexual $y$, finalmente, por casos judiciales montados por fuera de las universidades, o por parte de sobrevivientes, querellándose contra las universidades por su falta de acción y discriminación, o por empleados desvinculados de las universidades, después de fallos internos en su contra por acoso sexual, y que buscaban indemnizaciones y otros tipos de recompensa por supuestos prejuicios (Chi Cantalupo y Kidder, 2017; Kelley y Parsons, 2000; Kihnley, 2000).

Sobre este último tipo de acción judicial, Nancy Chi Cantalupo y William Kidder han desarrollado investigaciones particularmente interesantes sobre la figura del "académico acosador en serie", aquel tipo de académico acosador que es reincidente y que fue denunciado en el Congreso de EEUU en el año 2016 como la figura clave en los casos de "pasar el acosador" (pass the harasser), que es cuando, "un académico se mueve de una universidad a otra durante o después de una investigación por acoso sexual, sin enfrentar un castigo significante, o, incluso, castigo alguno" (Chi Cantalupo y Kidder, 2017, p. 851)'. Esto es posible, además, porque, como señala Jeannie Kihnley (2000), existe un "conflicto

1 Desde esta cita en adelante, todas las traducciones de inglés a castellano son de la responsabilidad de las autoras. 
inherente" dentro de las universidades, ya que la universidad quiere, simultáneamente, "eliminar el acoso sexual del ambiente laboral y escolar y protegerse de acciones legales (insulate itself from liability)" (Kinnley, 2000, p. 70).

A lo largo de casi cuarenta años de estudios sobre acoso sexual en las universidades a nivel global, varios puntos se siguen enfatizando, por ejemplo: (1) que es muy difícil establecer definiciones claras y consistentes sobre lo que constituye "acoso sexual" en las universidades, en el sentido de lo que se estipula pero también lo que se entiende por parte de los diferentes estamentos universitarios; (2) que las mujeres tienden a minimizar, negar y silenciar ser sobrevivientes de acoso sexual dentro de las universidades, por múltiples razones; y (3) que ciertas mujeres, en particular las más pobres, las racializadas y las LGBTQ+, entre otras categorías, están más vulnerables frente el acoso sexual. En última instancia, además, y como ya se planteó en el año 1982 Donna Benson y Gregg Thomson, el acoso no sólo tiene que ver con interacciones particulares entre personas o individuos propiamente tal, sino que también contribuye a la mantención del heteropatriarcado dentro de la educación superior: "las estudiantes mujeres enfrentan la posibilidad de que los instructores hombres manipulen el interés sexual y la autoridad en pos de promover prácticas que, a la larga, terminarán socavando la posición de las mujeres en academia. Hoy en día ya no se puede negar, abierta y legalmente, el acceso a la capacitación educacional y profesional para las mujeres; por tanto, el acoso sexual podría perdurar como un factor particularmente crítico relacionado con un tipo de discriminación más encubierta" (Benson y Thomson, 1982, p. 240). Veinte años después, Jeannie Kihnley encontró algo similar, al declarar que:

"la realidad de la educación superior es que las mujeres - quienes son, generalmente, las víctimas del acoso sexual - están en puestos académicos o laborales de subordinación, mientras los hombres - quienes, son, generalmente, los acosadores - tienen puestos de poder dentro de las instituciones académicas" (Kihnley, 2000, p. 89).

Es relevante mencionar que, hasta ahora, en Chile no existe una ley específica sobre el acoso sexual en las universidades ${ }^{2}$, ni tampoco una ley integral de violencia de género, aunque muchos grupos feministas anti-violencia la han exigido desde hace un tiempo (El Mostrador, 2020). En lugar de eso, Chile tiene una serie de leyes más bien enfocadas en la violencia intrafamiliar y el femicidio, pensadas desde esquemas familistas, cis-género y heterosexistas (Hiner, 2019a, 2020). Siguiendo una línea de análisis similar, se podría intuir que un enfoque pronunciado en la violencia de género que ocurre dentro de contextos de relaciones íntimas y las familias ha marginalizado discusiones sobre violencias que acontecen en otros ámbitos, como el trabajo o los estudios. Durante mucho tiempo la única forma de abarcar el acoso sexual fue dentro de contextos laborales, ya que existe una tipificación de acoso laboral en el Código de Trabajo, que incluye en su definición un apartado sobre acoso sexual. Según el Código del Trabajo, artículo 2, inciso 2:

2 Si existe un proyecto de ley - Ley de Acoso Sexual en la Educación Superior - que fue presentado en mayo de 2018 por la Red de Investigadoras y que contó con el apoyo de las senadoras Ximena Órdenes, Isabel Allende y Yasna Provoste. Hasta el momento de publicación sigue en tramitación; recién en diciembre 2020 fue aprobado unanimamente en la Cámara de Diputados y vuelve a comisión. Más adelante en el artículo lo comentaremos en relación a la Redl. 
"Se produce acoso sexual cuando un trabajador o empleador, realiza de manera indebida y por cualquier medio, solicitudes o requerimientos de carácter sexual no consentidas o aceptadas por la persona afectada (víctima) y generan un ambiente ofensivo en el trabajo, que amenaza o perjudica su situación laboral y oportunidades de empleo. Se puede entender por conductas de acoso sexual los siguientes ejemplos: - Acercamientos o contactos físicos no consentidos. - Propuestas verbales de carácter sexual. - Regalos con connotaciones románticas o físicas no aceptados. - Correos electrónicos o cartas personales con requerimientos sexuales, etc." (Dirección de Trabajo, 2020).

En el año 2016 el Ministerio de Educación (MINEDUC) publicó Protocolos contra el acoso sexual en educación superior: sugerencias para su elaboración en el que se reconoce el acoso sexual como una forma de violencia de género. Sin embargo, no fue hasta la acción y denuncia de las organizaciones feministas universitarias de estudiantes, académicas y funcionarias, la que obligó a que las instituciones de educación superior tuvieran que construir sus protocolos de género para enfrentar estas y otras situaciones relacionadas con la violencia y desigualdad de género. Es así como al día de hoy existen protocolos de género en casi todas las universidades públicas y privadas.

Sin embargo, como ha demostrado un estudio sobre los protocolos de acoso sexual en las universidades chilenas, hecho por Ana Luisa Muñoz-García, Liz Jackson y Luna Follegati (2018), la mayoría de estos son muy restrictivos, individualistas y reactivos, en el sentido de sólo reaccionar frente casos individuales bien definidos. Como ellas señalan: "Al tratar un incidente reportado de acoso sexual como un evento singular e irrepetible provocado por individuos de la comunidad académica, la universidad minimiza su responsabilidad y mantiene su reputación al cambiar o mover al individuo de la institución" (Muñoz-García et. al, 2018 , p. 3). Además, de esta forma, dejan fuera cuestiones más espinosas sobre brechas de género y poder dentro de la universidad, el consentimiento y las relaciones sexo-afectivas y una mirada feminista interseccional capaz de hacer cruces con otras variables, como orientación sexual, clase, raza/etnicidad, identidad de género, etc. (Muñoz-García et. al., 2018 , p. 4). Esto es particularmente importante porque, en general, las instituciones estatales a cargo de temáticas de educación, investigación y género (como MINEDUC, Ministerio de Ciencia y, Ministerio de la Mujer y la Equidad de Género), el Consejo de Rectores (CRUCH), y las universidades chilenas han sido muy lentas y parciales a la hora de incorporar políticas internas y externas sobre brechas de género y posibles puntos de conflicto, tales como el acoso sexual o la escasa presencia de mujeres en posiciones de poder dentro de las universidades (Robert, Pitzer y Muñoz-García, 2018; Troncoso, Follegati y Stutzin, 2019). Como señala Varela Guinot (2020), esto se debe a que hablamos de espacios generizados, lo que implica que si bien se han incorporado algunas demandas planteadas por los movimientos de mujeres y feministas "estos se han dado sin cuestionar la manera en que se articulan las relaciones al interior de la organización, tampoco se ha cuestionado el peso que puede tener la estructura de género" (Valera Guinot, 2020, p. 50). 
Frente este escenario de acoso sexual en las universidades, tan complejo y difícil de abarcar, ¿qué se puede hacere Una posible respuesta localizamos en la teoría feminista interseccional, adonde la construcción de coaliciones y redes densas es fundamental a su práctica. Un componente importante de la teoría feminista interseccional es la capacidad de construir coaliciones feministas en torno a problemáticas específicas que abarcan diferentes temáticas, pero particularmente en cuanto los cruces entre género, clase, orientación sexual, y raza/etnicidad (Crenshaw, 1991; Hill Collins y Bilge, 2016; Lykke, 2010). Esto es particularmente difícil porque conversaciones sobre racismo dentro de círculos feministas suelen ser complejas y, hasta, dañinas, particularmente para feministas no blancas que tienen que aguantar el racismo y el clasismo de sus supuestas "compañeras" blancas (Ahmed, 2017; Hooks, 1984; Lorde, 2007). Respecto el acoso sexual y las universidades, Sara Ahmed ha trabajado específicamente como las feminist killjoys (traducido como "aguafiestas feministas") emergen en academia, en muchos casos, justo a la hora de trabajar temáticas de género, sexualidades y feminismo (como women's studies), de trabajar temas de "diversidad", y a la hora de denunciar casos de acoso sexual, y cómo éstas se cansan y se vuelven frágiles por la naturaleza demandante, estresante y exhaustiva de este trabajo (Ahmed, 2017). En este contexto, entonces, es aún más clave y, hasta, necesario, poder estrechar lazos y crear redes con otres feministas, como medida para maximizar fuerzas a través de coaliciones y trabajar proyectos feministas en conjunto, aun siendo difícil.

\section{Materiales y métodos ${ }^{3}$}

En este artículo ocupamos principalmente análisis de prensa ${ }^{4}$ y declaraciones digitales producidas durante los años 2016 a 2018, en el contexto del Tsunami Feminista, como también trabajamos en la línea de grupos de discusión y entrevistas semiestructuradas. Asimismo, se trata de una investigación que reivindica la premisa del conocimiento situado, en el que las propias investigadoras integran de manera activa el movimiento feminista y son fundadoras e integrantes de la Red de Historiadoras Feministas. Esta perspectiva epistemológica feminista, a decir de Haraway, "trata de la localización limitada y del conocimiento situado, no de la trascendencia y el desdoblamiento del sujeto y el objeto" (1995, p. 327), lo que permite comprender y problematizar el rol del/la investigador/a en el proceso de construcción de conocimiento.

Entre los meses de agosto 2019 y enero 2020, se realizaron cinco grupos de discusión:

3 Esta investigación se enmarca en el proyecto Anillo SOC180007, "Political culture and Post-dictatorship: memories of the past, struggles of the present and challenges of the future" (2018-2021) que está en desarrollo. En conjunto las dos investigadoras, como investigadora titular y asistente del proyecto, están a cargo de la línea dos, "Collective action, social actors and memory disputes" que se enfoca en los nexos entre el movimiento estudiantil, el movimiento feminista y el movimiento LGBTQ+ en Chile desde el año 2006 en adelante.

4 Para esta investigación se revisaron medios de prensa chilenos en versión digital, incluyendo prensa tradicional (El Mercurio, La Tercera) y alternativa (El Desconcierto, El Ciudadano, etc.), entre 2016 a 2020. 
Tabla 1: Grupos de discusión

\begin{tabular}{|l|l|r|l|l|}
\hline & Ciudad & Participantes & Fecha & Perfil \\
\hline Grupo 1 & Santiago & 5 & $01 / 08 / 2019$ & Feminismos universitarios \\
\hline Grupo 2 & Santiago & 7 & $12 / 08 / 2019$ & LGBTQ+ \\
\hline Grupo 3 & Santiago & 5 & $09 / 10 / 2019$ & Feminismos/LGTBIQ+ \\
\hline Grupo 4 & Santiago & 6 & $12 / 12 / 2019$ & Feminismos \\
\hline Grupo 5 & Valparaíso & 5 & $13 / 01 / 2020$ & LGBTQ+ \\
\hline $\begin{array}{l}\text { Total asis- } \\
\text { tentes }\end{array}$ & & 28 personas & & \\
\hline
\end{tabular}

Fuente: elaboración propia

Participaron en total 28 personas, entre estudiantes de universidades públicas y privadas, de institutos profesionales, activistas de organizaciones LGBTQ+, profesionales universitarias y trabajadoras. Del total, 23 viven en la Región Metropolitana y las/os 5 restantes en Valparaíso. El acceso de las/os participantes se realizó en base a un muestreo no probabilístico, donde se invitó a participar a personas que cumplieran con las características de cada grupo. Debido al Estallido Social de octubre 2019, y sus consecuencias, los grupos 4 y 5 se retrasaron en su realización, lo que permitió incorporar al debate los acontecimientos más recientes que impactaron al país.

Los grupos de discusión se plantean como una herramienta metodológica cualitativa que tiene como objetivo proponer "una conversación que desarrolla un tema propuesto por el investigador" (Canales, 2006, p. 270). En ese sentido, el debate de los grupos de discusión se estructuró a partir de reunir a grupos de entre 5 a 7 personas, de edades y características similares relacionadas con ser estudiantes, activistas o profesionales - en los que, tras una breve presentación que tuvo como objetivo tensionar la relación entre feminismo/movimiento LGBTQ+ y democracia en el contexto de la postdictadura chilena- se abría el diálogo e interacción entre participantes. En esta metodología, a diferencia de los grupos focales, las facilitadoras intervienen poco en el debate, ya que se busca promover debate y reflexiones propias dentro del grupo de discusión, y así profundizar representaciones colectivas que expresan sentidos sociales más amplios (Canales, 2006; Rogel-Salazar, 2018).

En cuanto a las entrevistas, entre enero y octubre de 2020 se realizaron 6 entrevistas semiestructuradas con informantes clave, a partir de una selección no probabilística que tuvo como criterios de selección a mujeres destacadas como dirigentas políticas (diputadas, militantes de partidos políticos), sociales (asambleas territoriales, organizaciones estudiantiles) y académicas (redes feministas). La entrevista "se define como una conversación que se propone un fin determinado distinto al simple hecho de conversar" (Díaz-Bravo, et. al., 2013). El derrotero de los grupos de discusión y las entrevistas abordó temas como el movimiento feminista actual, la historia del feminismo chileno, el Tsunami Feminista, los diálogos y tensiones entre los movimientos feministas y de la diversidad/disidencia, las críticas y 
expectativas desde el activismo hacia la democracia y la política tradicional, la relación con otros movimientos sociales, entre otros temas. Los grupos de discusión y las entrevistas se realizaron bajo un estricto protocolo de ética y con cartas de consentimiento.

\section{Resultados}

A continuación, presentamos los resultados de la investigación, que están organizados en torno a las dimensiones que nos propusimos abordar en este artículo: el análisis del Tsunami Feminista, las estrategias y programas contra el acoso y la violencia en las universidades y, la emergencia de coaliciones y redes diversas (entre académicas, estudiantes, funcionarias, etc.) para fortalecer el movimiento.

\section{Acoso sexual y organización feminista estudiantil}

Como ya señalamos, la violencia y el acoso al interior de las instituciones de educación superior se visibilizó a partir de las denuncias de estudiantes en los años 2015/2016 y que explotan con fuerza en mayo de 2018. Como señala una participante de los grupos,

"...me organizo porque no quiero que se olvide que estamos en esta constante dinámica, oye si no saco la voz por un compañero o yo misma que sigo violentada nadie la va a sacar (...) si la mujer no denuncia nadie va a ir a denunciar por ti o nadie te va a decir sabí que estay siendo violentada..." (Grupo 3, Santiago, 9/10/2019).

Asimismo, el rol de las secretarías de género y sexualidades, conformadas mayoritariamente por estudiantes y en las que se generan redes, se discuten estrategias y organizan actividades, fue fundamental en este proceso. Se estima en la prensa que estas organizaciones "recepcionaron el año pasado prácticamente una denuncia por día intermedio" (Publimetro, 2017). Como se planteó en un grupo de discusión:

"ahora hay conciencia no se po", de cosas tan mínimas, o sea igual grande, como de cuáles son los límites del acoso con los profes, el hecho de tener confianza, si el profe te hace algo podí tener un lugar que la secretaría que te va a apoyar y vamos hacer acompañamiento..." (Grupo 1, Santiago, 01/08/2019).

Respecto de las estrategias para visibilizar el acoso sexual universitario, fueron principalmente los paros, movilizaciones y tomas, en algunas de las cuáles no se permitía la presencia de varones (El Dínamo, 2018; La Tercera, 2018), que inclusive abarcaron a instituciones tradicionalmente conservadores como la Universidad de los Andes, Finis Terrae, del Desarrollo y Adolfo Ibañez. El movimiento fue tal que, tras dos meses de movilizaciones, se estaban investigando 132 denuncias de acoso de parte de profesores, estudiantes y funcionarios, en 16 planteles (La Tercera, 2018). 
El Tsunami feminista fue un hito importante para las estudiantes y organizaciones feministas estudiantiles, como señalan las participantes:

"... no tengo conocimiento que en alguna parte del mundo estalló un movimiento feminista e implicó tomas universitarias... asambleas (...) como que fue un movimiento como de verdad en un sentido como onda universidades en tomas feminista, con petitorio, con asamblea, con debate político (...) el Mayo Feminista igual se monta sobre eso, como que agarra una demanda que venía hace mucho tiempo atrás trabajándose desde el tema de educación no sexista, la violencia hacia la mujer, el tema de los profesores acosadores, un montón de cosas que venían hace tiempo Ni Una Menos, etc., pero que además se monta sobre toda una tradición de varios años de asamblea de toma de lo que venía siendo la movilización por la educación gratuita". (Grupo 3, Santiago, 09/10/2019).

"yo creo que las mujeres que estuvimos en las tomas feminista del año pasado de verdad con algo quedamos si éramos distintas después de esa toma, yo creo que hay una organización distinta o sea, veo compañeras que antes no, no eran movilizadas tenían otra visión, como que hubo un cambio, yo creo que si hubo un hito". (Grupo 3, Santiago, 09/10/2019).

Sin embargo, a pesar de los logros del movimiento, con la expulsión de académicos o la creación de protocolos de género, existe una mirada crítica y reflexiva respecto de los límites, tensiones y dificultades que enfrentaron las estudiantes, académicas y funcionarias movilizadas. Por un lado, el desgaste y cansancio al interior del movimiento, propio de varios meses de activismo:

"todavíaseguimosenlamisma, elmovimientose decayómucho, noestamosviendoresultados ahora, y no tenemos una estrategia política clara" (Grupo 1, Santiago, 01/08/2019)

"el nivel de frustración lo que tenemos que vivir este año en cuanto a la desmovilización por agotamiento de nuestros mismos compañeros movilizados" (Grupo 3, Santiago, 09/10/2019).

También, las divisiones entre estudiantes por la propia fragmentación del sistema educativo, entre estudiantes públicas, privadas, centros de formación técnica, etc.:

"lo que pasó si es como que el Mayo Feminista igual se vio distinto según en cada universidad (...) si bien había una demanda como general contra la violencia de género, como que cada universidad como que la interpretaba un poco como quería (...) la crítica que hace mucha gente como tanto la disidencia, como mujer, como de las mismas organizaciones políticas activas de las universidades es como todos peleamos por cosas distintas" (Grupo 3, Santiago, 09/10/2019).

Por otro lado, se reflexiona sobre la "estrategia", entendiendo que se trata de un proceso de aprendizajes colectivos, pero también de nuevos desafíos, en los que existe una visión autocrítica respecto de la necesidad de generar mayores vínculos, con otras mujeres y organizaciones fuera de la universidad.

"una de las cosas que pasa cuando una se pone a conversar con cabras y cabros que no participaron en la movilización es que ellos sienten efectivamente que nosotras nos encapsulamos po', que nos metimos tanto en esta onda de que oh, lo que fue la toma, construimos amistades, construimos lazos de confianza que yo creo que son sumamente importantes para construir algo político pero no se puede quedar 
ahí, como que creo ese es el primer paso de un avance más individual no más como abrirse a un movimiento social, pero faltó mucho" (Grupo 1, Santiago, 01/08/2019).

"yo lo miro más como a nivel universitario siento que esto igual fue súper como de la guata, explotó y había que hacerse cargo de esto, creo que este como ola, sí, creo que sí es importante y si marcó un hito, pero al menos en la Central quedó como una estela así muy pequeñísima de lo que fue el movimiento..." (Grupo 1, Santiago, 01/08/2019).

También se produjeron complejos debates internos en temas como si las tomas eran separatistas (sólo de mujeres), sí podían participar mujeres trans, el rol de las funas en la denuncia, entre otros temas. Además, muchas estudiantes movilizadas enfrentaron sumarios o amenazas de expulsión, como fue el caso de estudiantes en la USACH, "Las jóvenes indican que se han cursado más de tres tipos de investigaciones sumarias por distintas situaciones relacionadas a la visibilización de estos atropellos" (El Desconcierto, 2018), lo que también se repitió en otras universidades.

Si bien algunas tomas y paros incluyeron demandas más amplias, abordando la situación de las trabajadoras de limpieza o funcionarias, levantando demandas como fin al subcontrato o a la precariedad laboral, en los grupos de discusión se expresa la necesidad de salir de los espacios universitarios, para llegar a mujeres de otros sectores y clases sociales: mujeres migrantes, populares, trabajadoras:

"...hay una crítica incluso de las mismas feministas que participaron del Mayo Feminista "no es que fue un movimiento demasiado universitario" eh pero porqué por ejemplo no tomamos otro tipo de demandas que hubiesen permitido como estrechar lazos con no se po' desde los territorios hasta lugares de trabajo..." (Grupo 3, Santiago, 09/10/2019).

"pa' mi el feminismo es interseccionalidad cachay, entonces donde está el tema migrante, donde está el tema especista, donde está la pobreza, la vulnerabilidad relacionada con el feminismo ósea los grupos LGTBIQ+ y las mujeres somos las históricamente más vulneradas económicamente" (Grupo 5, Valparaíso, 13/01/2020).

Finalmente, la reflexión colectiva aborda los logros y límites del proceso, sus contradicciones y tensiones. Como señala una participante:

“... yo creo que los últimos años si hemos logrado ver cambios, ¿̇son los suficientes? por supuesto que no, nos siguen matando, nos siguen violando, nos siguen desapareciendo, pero hemos ido cambiando, hoy en día nadie puede decir abiertamente o que tire un chiste respecto a la violencia intrafamiliar de la mujer, porque es reprochado socialmente..." (Grupo 4, Santiago, 12/12/2019).

\section{Redes de profesionales feministas y coaliciones en torno al acoso sexual}

En abril 2016 un grupo de más de cien historiadoras, académicas y profesionales firmaron una carta pública, titulada, "¡Nunca más solas! hablan las historiadoras y académicas sobre acoso sexual en la Universidad" (El Mostrador, 2016). El propósito de la carta era, en gran medida, visibilizar el apoyo irrestricto del grupo hacia las denuncias de acoso sexual 
que transcurrían en las universidades, y, con particular fuerza, dentro de departamentos de Historia. En la carta se planteaba las similitudes entre las experiencias del machismo de estudiantes y académicas/profesionales:

"Como historiadoras mujeres, muchas de nosotras hemos pasado por situaciones similares, sino iguales, en nuestras propias formaciones académicas o hemos sido testigos de reiteradas situaciones de misoginia y machismo dentro de nuestras instituciones de estudio y trabajo" (El Mostrador, 2016).

Destacamos esta carta, publicada al calor de los primeros sumarios contra acosadores en las universidades, como también luchas importantes de estudiantes feministas, ya que presenta ideas que van a ser retomadas por diferentes organizaciones y redes feministas en años posteriores. Es decir, en primera instancia, ver en las luchas estudiantiles feministas demandas que tienen que ver con las propias subjetividades y experiencias de mujeres mayores (ya no estudiantes) pero con clara conciencia de lo complejo y sesgado de su formación en espacios universitarios, como también de cómo esas violencias también pueden ser ejercidas contra mujeres académicas, administrativas y auxiliares en las universidades. Una integrante de la Red de Investigadoras, por ejemplo, recordó, con claridad, un episodio de violencia sexual, ejercida contra una compañera de estudios en la universidad:

"Una de las cosas que más me marcaron, y marcaron a todas en esa generación, fue un intento de violación de parte de un profesor a una compañera. Y eso se disfrazó como que era algo con sentido; ella andaba con mucho trago y andaba con su esposo que era tesista de este profesor. Era para un 18 que habían hecho una fiesta en su casa, en la casa del profe. Todas esas cosas te van marcando" (Entrevista con integrante de Redl, 23/10/20).

A la vez, también se propone un trabajo conjunto entre académicas, estudiantes y otros sectores, en pos de llevar a cabo los cambios requeridos dentro de las universidades. Frecuentemente esto toma la forma de alianzas intergeneracionales entre mujeres; las académicas las forjan ahora con sus estudiantes porque, en el pasado, cuando eran estudiantes, también habían mantenido relaciones así con otras académicas, aunque fuesen pocas en ese entonces. Así nos cuenta una integrante de la Red de Docentes Feministas:

"Yo tengo una compañera de universidad con la que estudiamos, nos conocemos hace veinte años ya, (...) vivimos toda esa etapa de que los profes nos decían que las mujeres de filosofía (...) nos teníamos que dedicar a temas de educación, que la filosofía era para hombres -así muy explícito- (...) llegar a la universidad y que un compañero me dijera que era más tonta porque era mujer y cosas por el estilo, fue como "¿qué te pasa?" (...) Yo creo que ese encuentro con otras mujeres fue fundamental y fue en la universidad (...) cuando yo entré a filosofía (...) había solo una académica. Bueno, en muchos Departamentos de Filosofía en Chile todavía es así, digamos. Entonces uno establecía una relación solidaria con ellas y se van construyendo cosas" (Entrevista con integrante de Redofem, 22/2/20).

A la misma vez, para el año 2016, se empezaron a visibilizar no sólo casos de acoso sexual contra estudiantes sino también contra académicas y auxiliares. Esto se vio con particular fuerza en la Universidad Austral, ubicada en Valdivia, en el año 2017. Ahí surgió tal vez el caso más 
reconocido de acoso sexual en la UACh, cuando el bioquímico Alejandro Yáñez fue acusado por múltiples instancias de acoso sexual (Red de Investigadoras, 2017). Este caso se volvió mediático, siendo tempranamente denunciado por la Red de Investigadoras y cubierto por múltiples medios nacionales e internacionales, incluyendo la revista Science. El caso Yáñez se destaca no sólo por los abusos, sino también por la inoperancia de la universidad y el sistema judicial. En abril 2018, la UACh lo suspendió de la docencia durante dos años, pero le permitieron seguir con sus investigaciones. Un mes después, en mayo 2018 estalló el "Tsunami Feminista" y las primeras movilizaciones estudiantiles feministas acontecieron, justamente, en la UACh. En ese contexto Yáñez fue desvinculado de la universidad, pero él argumentó en tribunales que la UACh no podía castigarlo dos veces por el mismo delito (en este caso, acoso sexual) y ganó. Así, lo tuvieron que reincorporar como académico (Wessel y Perez, 2019).

En conjunto con esto, diferentes redes formales e informales de académicas feministas empezaban a trabajar en conjunto entre ellas y con diferentes organizaciones feministas y partidos políticos, en pos de situar el tema de el machismo y el acoso sexual en el Estado. En enero 2018, se publicó una carta, firmada por la Redl, más 139 académicas y estudiantes, que pedía que Conicyt, la institución en ese entonces responsable para la investigación en Chile, velara por la adjudicación de fondos prestigiosos de investigación a académicos no condenados por la violencia de género o el acoso sexual (El Mostrador, 2018). Poco después, en marzo 2018, la Redl participó en la jornada "Diálogos para una educación no sexista" en el ex Congreso Nacional en Santiago con las diputadas Camila Rojas, Camila Vallejo y Cristina Girardi, visibilizando el proyecto de ley recién introducido con la ayuda de Redl sobre acoso sexual en contextos educativos (Nueva Mujer, 2018).

A lo largo del año 2018, Redl hacía lobby para introducir una ley de acoso sexual en el Congreso, como también promover políticas de género dentro del Ministerio nuevamente establecido, el Ministerio de Ciencias, Tecnología, Innovación y Conocimiento (MICITEC), reemplazando lo que anteriormente había sido Conicyt (Redl, 2018). Aquí, en el contexto del lobby y las discusiones legislativas, algunos miembros de la Redl, como la presidenta, Adriana Bastías, la vice-presidenta, Vania Figueroa y algunas integrantes, como Mónica Vargas, se hacían presentes y más conocidas públicamente. En el caso de Vargas, por ejemplo, una cuña suya se volvió viral, cuando el entonces Ministro de Educación, Gerardo Varela, refirió al acoso sexual en las universidades como "pequeñas humillaciones" en la Comisión de Educación del Senado. Vargas lo interpeló, señalando al ministro que, "las humillaciones no son pequeñas, yo no puedo dejar pasar las palabras del ministro de Educación (...) Las humillaciones son tremendas. Nosotros como investigadoras, académicas, doctoras, pos doctoras en ciencias sociales, en bioquímica, hemos sufrido las humillaciones más tremendas que se pueda imaginar al interior de las universidades" (Hansen, 2018).

No por nada, el comentario del ministro sobre las "pequeñas humillaciones" aconteció justo durante lo más álgido del Tsunami Feminista, lo cual amplió aun más las repercusiones de estos comentarios. Por el contexto de rápida y profunda movilización de estudiantes feministas y disidentes sexuales, muchas académicas y profesionales también sentían el 
llamado a hacer más que sólo apoyar a las mujeres más jóvenes. En muchos casos, estas organizaciones y redes profesionales nacieron desde momentos de profunda reflexión por parte de mujeres sin tanto tiempo fuera de las universidades - o que todavía estaban en las universidades, pero ahora como docentes o académicas - y con memorias frescas del machismo y el acoso sexual en esos entornos. Algunas redes ya existieron, como la Red de Historiadoras Feministas (RHF) que se formó en el contexto de las Jornadas Nacionales de Historia en Valdivia en octubre 2017, impulsada por los casos de acoso sexual en los departamentos de Historia. Por lo mismo, ya para mayo 2018 la RHF pudo publicar una declaración explicitando su apoyo hacia el "Mayo Feminista" y sus demandas:

\begin{abstract}
"Reconocemos y valoramos el camino que este movimiento feminista-estudiantil abre en el país, la discusión en torno al feminismo, transitando de las reivindicaciones y las acciones para la regulación de la violencia hacia la construcción de un proyecto de sociedad que supere las estructuras de opresión por razones de género, clase, raza, etnicidad, u orientación sexual (...) Como historiadoras feministas, además, observamos con particular atención la manera en que el machismo, la misoginia, el racismo y el heterosexismo han permeado nuestra Historia y nuestra forma de trabajar esa Historia dentro de las universidades" (La Izquierda Diario, 2018).
\end{abstract}

No obstante, esta temprana organización por parte de la Redl y la RHF, va a ser el Tsunami Feminista que va a impulsar la creación de muchas otras redes profesionales. Por ejemplo, durante el 2018 se creó la Red de Docentes Feministas (Redofem), liderada por Rosario Olivares, una profesora feminista conocida por haber sido directora del Colegio Latinoamericano y, por haberse presentado como candidata a diputada por un partido del Frente Amplio en el 2017; y, entre febrero y marzo 2019 aparece la organización Abogadas Feministas de Chile (Abofem), llegando a las noticias por su trabajo con las sobrevivientes del ciber-acoso del grupo Nido. También se han constituido la Red de Periodistas Feministas (Redperiofem); Red de Matronas Feministas (Matrofem); Red de Sociólogas Feministas (Redsofem), entre otras.

Al hablar de la formación de Abofem, su directora, Bárbara Sepúlveda, señaló, "Comenzamos a debatir sobre la falta de una instancia en nuestro gremio que fuera estable y representativa en la cual pudiéramos aportar al movimiento (...) Abofem resultó ser para muchas abogadas el espacio donde queríamos estar y que hasta entonces no existía" (Aguilera, 2019). En una entrevista una integrante de Redofem también destaca las contribuciones que aportan las redes de profesionales feministas al movimiento feminista:

"Yo creo que una de las cosas interesantes que sacó el feminismo en esta última movilización fueron estos nuevos tipos de organizaciones, que son profesionales en el caso de estas (...) ayuda a resolver la precarización de la propia vida, que es como poner al servicio tu profesión, tu trabajo de la lucha feministas (...) me parece que eso tiene harta proyección y yo diría que en la medida que los partidos quedan sin militantes, ese tipo de organizaciones van teniendo cada vez más realce" (Entrevista con integrante de Redofem, 22 de febrero de 2020). 
Finalmente, la continua vulnerabilidad de las mismas mujeres académicas y profesionales frente el acoso y la violencia dentro de sus entornos de estudio, trabajo e investigación también es un factor no menor en la organización de redes. Si al principio, durante los años 2017-2018, esto, generalmente, se manifestaba en torno a casos ya vividos en el pasado o de la extensión de la denuncia desde las organizaciones hacia las personas afectadas, como en el caso de la Redl con el caso Yáñez o la RHF con las estudiantes del Mayo Feminista, para el año 2019 llegó a manifestarse directamente en un caso escandaloso de dos académicas de la Redl que fueron desvinculadas por denunciar acosos y abusos en su universidad, Karina Bravo y Vania Figueroa, esta última la vice-presidenta de la Redl (Salinas, 2019). Ambas académicas, doctoras y neurocientíficas, trabajaron en el Instituto de Ciencias de la Salud de la universidad regional recién fundada Universidad de O'Higgins. Karina Bravo presentó una queja por acoso en junio de 2018, lo cual tenía aspectos de discriminación laboral por edad y género, y durante el proceso, Figueroa testificó a su favor. El 7 de diciembre de 2018, ambas fueron desvinculadas por mail, citando una evaluación extremadamente arbitraria y sesgada de "baja productividad académica" (Hiner, 2019b).

Hasta la fecha de escritura de este texto, Figueroa mantiene una demanda por tutela laboral en tribunales, pero la experiencia para ambas académicas, aun con el apoyo irrestricto de la Redl, estudiantes y académicos/as de la Universidad de O'Higgins y académicos/as y científicos/as dentro de y fuera de Chile, ha sido demoledora. No obstante, aunque el caso específico de Vania y Karina no ha obtenido resultado favorable, también ilustra el poder de las redes profesionales. De alguna manera, a falta de resultados positivos en la universidad o tribunales, terminan siendo las redes profesionales feministas las que juegan un rol reparatorio, a la hora de reconocer el daño, actuar colectivamente y combatir el individualismo y el silencio. De esta forma, podemos notar un paralelismo con organizaciones feministas estudiantiles, aunque tal vez en otros registros y con otras repercusiones. Una integrante de la Redl reflexionó sobre esto:

"A mí me parece genial que se vayan formando además ciertas interacciones entre las redes, apoyos y complicidades dentro de las redes. Creo que es una forma de organización que es importante, que es interesante y que tiene que ver también con una lucha de poder. No vas a ser reconocida sola ni en conjunto, pero en conjunto puedes ser capaz de coordinar y de articular ciertas situaciones. Es importante la organización (...) y es una lucha que tiene que ver con la resistencia al sistema neoliberal donde todo es individualismo" (Entrevista con integrante de Redl, 23 de octubre de 2020). 


\section{Discusión y conclusiones \\ ¿Nunca más solas? Consecuencias a más largo plazo del Tsunami Feminista y la posibilidad de mantener vigentes nuevas coaliciones y redes feministas}

Este artículo se propuso el objetivo de analizar el Tsunami Feminista de 2018, explorando las resistencias y estrategias para visibilizar y cuestionar el acoso y la violencia sexual, planteando como hipótesis que el surgimiento y la consolidación de nuevas redes y coaliciones impulsaron una denuncia potente de la violencia/el acoso sexual dentro de las universidades y promovió la creación de un frente feminista intergeneracional fuerte en torno esta temática, poco trabajada hasta ese momento.

Los resultados de la investigación permiten concluir que el Tsunami Feminista permitió visibilizar las situaciones de acoso y violencia sexual al interior de las universidades de impactante manera, creando protocolos y departamentos de género, tal como da cuenta el estudio realizado por MINEDUC y ONU Mujeres, "Equidad de Género en la Educación Superior", que señala los cambios producidos tras los procesos de movilización del Tsunami Feminista de 2018. Del total de universidades que respondieron la encuesta, "nueve de cada 10 universidades cuenta hoy con un protocolo frente al acoso sexual o violencia de género"; hace tres años atrás, "apenas seis universidades tenían protocolos. Hoy, en cambio, hay 41 . Es decir, 93\% de las universidades y $64 \%$ de centros e institutos los poseen" (Fernández, 2020). Por otro lado, tras el impacto del Tsunami Feminista, instituciones como la Cámara de Diputados y el Poder Judicial también implementaron o realizaron cambios en sus protocolos de género (Ferrer, 2020).

Los grupos de discusión en los que participaron estudiantes y activistas que fueron parte del proceso, valoran la visibilidad del movimiento y el haber instalado en el debate público estos temas, el que es considerado un hito del movimiento feminista, como también la vivencia y experiencia que realizaron las participantes del movimiento. Sin embargo, se observa una autocrítica respecto de las debilidades, debido al encapsulamiento que se vivió en los procesos locales de cada universidad, como también el poco contacto con otros sectores (académicas, funcionarias, mujeres fuera del espacio universitario), que solo alcanzaron a desarrollar diálogos incipientes triestamentales. Además del desgaste del movimiento, que enfrentó también los sumarios, divisiones internas y otros problemas, la sensación de que aún queda mucho por hacer es persistente. Por otro lado, el surgimiento y/o consolidación de redes de académicas y profesionales feministas evidencia la profundidad del fenómeno de la violencia y el acoso, que afecta por igual a las mujeres de distintos estamentos. Estas redes fueron relevantes para instalar y extender el tema también a nivel institucional en Conicył (hoy ANID), como en diálogos con parlamentarias y partidos como el Frente Amplio o el Partido Comunista, discutiendo también la necesidad de una ley contra el acoso sexual, entre otras cosas.

Respecto de las estrategias y resistencias utilizadas por estudiantes, académicas y profesionales feministas, estas incluyeron la denuncia activa institucional y en redes sociales, como también acciones como paros, tomas de recintos universitarios, marchas y movilizaciones locales y nacionales. En cuanto a las organizaciones, cumplieron un papel 
importante las asambleas y las vocalías y secretarías de género y sexualidades, como también -posteriormente- las redes profesionales feministas. De esta manera tanto las estudiantes, como también las académicas y profesionales, se volvieron feminist killjoys (Ahmed, 2017) en sus respectivos espacios, denunciando el acoso sexual y las desigualdades de género, incluso en contextos adonde iban a enfrentar serias consecuencias, como la expulsión o el despido. Tal vez lo más interesante, además, ha sido el "espejismo" de estrategias entre estudiantes y profesionales feministas, adonde las profesionales son, en el fondo, ex estudiantes que ahora llevan lo aprendido en las universidades hacia el mundo profesional y las coaliciones feministas a futuro. Algunas, las más jóvenes, hasta vivieron algo de las movilizaciones estudiantiles universitarias, o como estudiantes de pre o postgrado. Pero incluso las "no tan jóvenes" también tuvieron cercanía con los grandes cambios políticos que han ido transformando Chile dentro de los últimos quince años.

Estos aprendizajes y experiencias colectivas - tal vez no tan impregnadas de "feminismo" al principio - posteriormente van a moldear un estilo de participación política, crítica al neoliberalismo y la democracia de los acuerdos, que va a permear casi todos los ámbitos feministas de los últimos diez años y, a la vez, el feminismo también va a teñir todos esos espacios de participación política. Es evidente que la universidad ha sido un espacio, en particular, tensionado y cuestionado desde estas nuevas lógicas, tanto por su neoliberalismo (Donoso Díaz, 2005; Oyarce, Leihy y Zegers, 2020), como también por sus jerarquías institucionales y epistemológicas basadas en el heterocispatriarcado y el racismo. Mientras siguen existiendo resistencias y rechazos del feminismo y frente temas de acoso sexual y las brechas de género, incluso por parte de mujeres, es innegable que actualmente hay muchas más estudiantes, académicas y profesionales feministas que levantan la voz desde las universidades y otros espacios territoriales. Esto ha posibilitado nuevas e interesantes redes y coaliciones feministas que siguen vigentes hasta el día de hoy.

A modo de cierre, es también importante destacar que el Tsunami Feminista se inscribe en un contexto más amplio en el que los movimientos feministas y LGBTQ+ han marcado la agenda política de los últimos años y, en particular, han estado muy presentes en el reciente proceso de estallido y revuelta social. La performance del colectivo Las Tesis, "Un violador en tu camino", que se presentó para la conmemoración del 25 de noviembre de 2019, Día Internacional de la NO Violencia Contra la Mujer, se viralizó rápidamente, siendo reproducida por miles de mujeres en distintos idiomas y países. Asimismo, los pañuelos verdes y lilas, y la bandera de la diversidad sexual, estuvieron entre las más utilizadas en las movilizaciones desde octubre de 2019 en adelante. Esto se expresó también en la promulgación de la paridad de género para el proceso constituyente, algo inédito en el mundo.

No obstante, como historiadoras feministas, coordinadoras de la Red de Historiadoras Feministas y muy involucradas en los procesos sociohistóricos hasta aquí analizados, tenemos bastantes dudas y aprehensiones sobre lo que viene. Por un lado, existen problemas reales con la manera en que se están implementando los protocolos y llevando a cabo procesos por acoso sexual en las universidades. Por conflictos del tipo mencionado aquí, al revisar el 
caso de Yáñez en la UACh, muchas veces son los mismos acosadores que terminan ganando en tribunales y/o recibiendo altos montos de dinero como indemnización por "despido injustificado" u otras razones. Esto ya se había visto en la bibliografía sobre casos en Estados Unidos y también ocurre en el caso chileno. Tal vez en Chile incluso haya sido más complejo el tema: recién una decisión de la Corte Suprema señaló que insinuaciones y tocaciones físicas no eran actos "suficientemente controvertidos" como para ser acoso sexual (CNN, 2020). A la par con esto, muchos acosadores han llevado sus acusadoras a tribunales por injurias, calumnias u otras razones vinculadas con el "daño a su honor"; de hecho, esto mismo está pasando actualmente con una de las autoras de este artículo (querella criminal en su contra por injurias). Estos casos crean un alto grado de estrés y un gasto innecesario de energía y recursos para las mujeres denunciantes; de alguna forma, sirven como "factor disuasivo" para que las mujeres a futuro no denuncien. Y, finalmente, también ha habido expulsiones de estudiantes y despidos de académicas y mujeres profesionales justamente por denunciar el acoso sexual en sus entornos. Ya vimos esto en el caso de Vania y Karina, pero sigue pasando, incluso en un contexto de pandemia y adonde las afectadas tienen muy pocas posibilidades de levantar defensas públicas y organizarse bien, justo por el cierre físico de la mayoría de las universidades y la transferencia de las clases a plataformas online (Fossa, 2020).

Sin duda, todavía estamos muy lejos de una justicia reparadora o feminista en cuanto el acoso sexual. Además, y por encima de esto, también ha habido cada vez más cuestionamientos sobre los protocolos y las sanciones de por sí. ¿̇Nuestras opciones sólo pueden ser punitivistas, en el sentido de "castigar" a los culpables después del acto? ¿ O podríamos tratar de repensar nuestros espacios de estudio y trabajo más bien desde lógicas pedagógicas y éticas feministas? ¿Cómo se vería una universidad así y cuáles serían nuestros roles como académicas feministas en ese contexto? La "Coronacrisis" del COVID-19 también nos hace reflexionar sobre tensiones siempre presentes en la academia y la sociedad que han sido potenciadas por nuestro contexto pandémico. Muchas mujeres académicas se sienten totalmente sobrepasadas por las demandas de teletrabajo y los cuidados de niñes, adultos mayores y personas enfermas (Figueroa, 2020). Casos de violencia de género y violencia contra personas LGBTQ+ en las casas durante las cuarentenas han ascendido rápidamente; llamadas al fono VIF (1455) aumentaron un $179 \%$ en comparación con el año 2019 (T13 móvil, 2020). En este contexto, sin duda, las redes feministas y las coaliciones son más importantes que nunca. Como redes que denuncian, pero también contienen y crean proyectos colectivos en conjunto. Desde el encierro forzado de la pandemia global se vuelve más importante que nunca recordar: "inunca más solas!". 


\section{Agradecimientos}

Este artículo forma parte del proyecto de investigación,"Political culture and Post-dictatorship: memories of the past, struggles of the present and challenges of the future," financiado por el fondo Anillo SOC180007. Se agradece a las ayudantes de investigación, María Graciela Acuña y Daniela Castro por su trabajo, como también a la transcriptora, María Rosa Verdejo. Además, las autoras agradecen el apoyo de sus familiares y amigxs durante estos duros tiempos pandémicos. Sin ellxs no habría sido posible escribir este artículo. Hillary en particular quiere reconocer a su madre y su hermana por haber ayudado con los cuidados de su hija.

\section{Bibliografía}

Acuña, E. y Montecino, S. (2018) "Bases para una educación no sexista". Docencia, (Santiago), (Año XXII), Recuperado de http://revistadocencia.cl/web/ images/ediciones/Docencia_62.pdf

Aguilera, P. (8 de marzo de 2019). La lucha de Abofem: Mujeres al centro de la justicia. CNN. Recuperado de https://www.cnnchile.com/8m/abofem-mujeres-justicia_20190308/

Ahmed, S. (2017). Living a Feminist Life. Durham: Duke University Press.

Alfaro, J. y De Armas, T. (2019). Estudiantes universitarias chilenas: discursos y prácticas contra la violencia sexista. Nómadas, (Universidad Central Colombia), 51 (a2), 31-47.

Alonso, C. (13 de agosto de 2020). "Más carga para la mujer: estudio reveló que casi el $40 \%$ de los hombres destinó 0 horas a la semana en actividades como cocinar, limpiar o lavar ropa". La Tercera. Recuperado de https://www.latercera.com/pulso/noticia/nada-ha-cambiado-en-cuarentena-los-hombres-aportan-muy-poco-tiempo-a-labores-del-hogar-el-cuidado-de-los-hijos-y-sU-educacion/73MAHJEYE5AVXOVTQNJNUOAZSA/

Badilla, M. (2019). The Chilean Student Movement: Challenging Public Memories of Pinochet's Dictatorship. Mobilization: An International Quarterly. 24 (4), 493510.

Benson, D. y Thomson, G. (1982). Sexual Harassment on a University Campus. The Confluence of Authority Relations, Sexual Interest and Gender Stratification. Social Problems, 29 (3), 236-251.

Bogart, K. y Stein, N. (1987). Breaking the Silence: Sexual Harassment in Education. Peabody Journal of Education, 64 (4), 146-163.

Canales Cerón, M. (2006). El grupo de discusión y el grupo focal. En M. Canales (coord), Metodologías de investigación social. Introducción a los oficios (pp. 265-287). Santiago: LOM.

Cárdenas, A. y Navarro, C. (2013). Redefiniendo límites, acortando distancias: el movimiento estudiantil en Chile. Santiago: RIL.

Castillo, A. (2016). Disensos feministas. Santiago: Editorial Palinodia.

Chi Cantalupo, N. y Kidder, W. (2017). Mapping the Title IX Iceberg: Sexual Harassment (Mostly) in Graduate School by College Faculty. Journal of Legal Education, 66 (4), 850-881.

CNN (23 de octubre de 2020). Corte Suprema revirtió expulsión de funcionario: No consideró insinuaciones y tocaciones como acoso sexual. Recuperado de https://www.cnnchile.com/pais/corte-suprema-insinuaciones-tocaciones-acoso-sexual_20201023/

Crenshaw, K. (1991). Mapping the Margins: Intersectionality, Identity Politics and Violence Against Women of Color. Stanford Law Review, 43 (6), 1241-1299.

Crocker, P. (1983). An Analysis of University Definitions of Sexual Harassment. Signs, $8(4), 696-707$.

De Fina, D. y Figueroa, F. (2019). Nuevos "campos de acción política" feminista: Una mirada a las recientes movilizaciones en Chile. Revista Punto Género, 
(11), 51-72. Recuperado de https://revistapuntogenero.uchile.cl/index.php/ RPG/article/view/53880

Díaz-Bravo, L.; Torruco-García, U.; Martínez-Hernández, M. y Margarita Varela-Ruiz. (2013). La entrevista, recurso flexible y dinámico. Investigación educ. médica, (México), Vol.2 (7), Recuperado de http://www.scielo.org.mx/scielo.php?script=sci_arttext\&pid=S2007-50572013000300009

Dirección de Trabajo. (2020). Acoso Laboral. Recuperado de https://www.dt.gob. $\mathrm{cl} /$ portal/1628/w3-propertyvalue-158257.html

Docencia (agosto 2018). Revista del Colegio de Profesores. (Año XXII (62), Recuperado de http://revistadocencia.cl/web/images/ediciones/Docencia_62. pdf

Donoso Díaz, S. (2005). Reforma y política educacional en Chile 1990-2004: el neoliberalismo en crisis. Estudios Pedagógicos, Año XXXI (1), 113-135. Doi: 10.4067/ S0718-07052005000100007

Duarte, C. y Rodríguez, V. (2019). Políticas de igualdad de género en la educación superior chilena. Rumbos TS, Año XIV (19), 41-72. Recuperado de http:// revistafacso.ucentral.cl/index.php/rumbos/article/view/328/381

Dziech, B. y Weiner, L. (1984). The Lecherous Professor: Sexual harassment on campus. Boston: Beacon Press.

El Desconcierto (13 de agosto de 2016). Declaración pública del Colegio de Periodistas por caso de acoso sexual en la U. Austral. Recuperado de https://www.eldesconcierto.cl/2016/08/13/declaracion-publica-del-colegio-de-periodistas-por-caso-de-acoso-sexual-en-la-u-austral/

El Dínamo. (23 de mayo de 2018). Movimiento feminista ya concentra 17 paros y 22 tomas en distintas universidades. Recuperado de https://www.eldinamo.cl/ educacion/2018/05/23/movimiento-feminista-ya-concentra-17-paros-y-22-tomas-en-distintas-universidades/

El Mostrador (10 de enero de 2018). Académicas y estudiantes realizan declaración: "Conicyt: ¡Basta de financiar abusadores y acosadores! Recuperado de https:// www.elmostrador.cl/braga/2018/01/10/academicas-y-estudiantes-realizan-declaracion-conicyt-basta-de-financiar-abusadores-y-acosadores/

. (21 de abril de 2020). Plataforma "Juntas en Acción" entrega propuestas al Senado sobre proyecto de ley de violencia integral. Recuperado de https://www.elmostrador.cl/braga/2020/04/21/plataforma-juntas-en-accion-entrega-propuestas-al-senado-sobre-proyecto-de-ley-de-violencia-integral/

Fardella, C. (2020). Abrir la jaula de oro. La universidad managerial y sus sujetos. Revista Izquierdas, (49), 2299-2320. Recuperado de http://izquierdas.cl/ediciones/2020/ numero-49

Fernández, O. (19 de octubre de 2020). Encuesta: 93\% de las universidades tienen hoy protocolos antiacoso sexual. La Tercera. Recuperado de https://www.latercera. $\mathrm{com} /$ nacional/noticia/encuesta-93-de-las-universidades-tienen-hoy-protocolos-antiacoso-sexual/QC6WYDPPYNELZLDJ42IJK3RHMA/

Ferrer, C. (8 de marzo de 2020). "A dos años del mayo feminista: Los primeros resultados de los protocolos contra acosos y abusos". EMOL. Recuperado de https:// www.emol.com/noticias/Nacional/2020/03/08/978896/Protocolos-acoso-como-han-funcionado.html

Figueroa, Natalia (6 de junio de 2020). "Coronamadres", el chat de mujeres que debaten sobre ser madres y trabajadoras durante la cuarentena. El Desconcierto. de https://www.eldesconcierto.cl/2020/06/06/coronamadres-el-chat-de-mujeres-que-debaten-sobre-ser-madres-y-trabajadoras-durante-la-cuarentena/

Follegati, L. (2016). 'Feminismo y Universidad de Chile', in Del Valle, S. (ed.). Educación no sexista. Hacia una real transformación. Santiago: Red chilena contra la violencia hacia las mujeres, 121-133.

. (2018). "El feminismo se ha vuelto una necesidad: movimiento estudiantil y organización feminista (2000-2017)," Revista Anales, 7 (14), 261-292.

Fossa, L. (5 de octubre de 2020). Docentes y estudiantes UDP denuncian represalias y despidos por tomas feministas de 2019. Interferencia. Recuperado de https://interferencia.cl/articulos/docentes-y-estudiantes-udp-denuncian-represalias-y-despidos-por-tomas-feministas-de-2019

Hansen, H. (16 de mayo de 2018). Ministro Varela se supera: Dice que acoso a mujeres son "pequeñas humillaciones". Infogate. De https://www.infogate. 
cl/2018/05/16/ministro-varela-se-supera-dice-que-acoso-a-mujeres-son-pequenas-humillaciones/

Haraway, D. (1995). Ciencia, cyborgs y mujeres: la reinvención de la naturaleza. Ediciones Cátedra. Madrid.

Hill Collins, P. y Bilge, S. (2016). Intersectionality. Cambridge: Polity Press.

Hiner, H. (2020). LGBTQ-IPV and the case for challenging maternalist family violence paradigms in Chile. En A. Ramm y J. Gideon (Eds.). Motherhood, Social Policies and Women's Activism in Latin America (pp. 195-218). Cham: Suiza: Palgrave MacMillan.

2019a). A Feminist History of Violence against Women and the LGBTQIA+ Community in Chile, 1964-2018. En: The Oxford Research Encyclopedia of Latin American History. New York: Oxford University Press. DOl: 10.1093/acrefore/9780199366439.013.665.

(2019b). Professors Test the Limits of "Me Too" in Chile, NACLA. Recuperado de https://nacla.org/news/2019/05/08/professors-test-limits-\%E2\%80\%9Cme-too\%E2\%80\%9D-chile

Hiner, H. y Troncoso, L. (en prensa). "LGBTQ+ Tensions in the 2018 Chilean Feminist Tsunami". Bulletin of Latin American Research.

Hiner, H. y Vivaldi, L. (2019). ¡Aborto libre ya! Nuevas generaciones de feministas y las luchas por el aborto en Chile. En K. Glavic (comp.). Aborto Libre. Materiales para la lucha y la discusión en Chile (pp. 73-95). Santiago: Pólvora.

Hooks, B. (2000 [1984]). Feminist Theory from Margin to Center (2nd edition). Cambridge: South End Press.

Huenulef, N. y Vargas, M. (2020). ¡Queremos educación que no lucre y no sexista! Movimiento feminista-estudiantil y prácticas contrahegemónicas en la historia reciente de Valdivia, Chile (2006-2018). Revista Izquierdas (49), 2777-2800. Recuperado de http://izquierdas.cl/ediciones/2020/numero-49

Jerez, C. (19 de diciembre de 2018). Estudiantes sumariadas arriesgan expulsión tras denunciar casos de acoso en la USACH: Decisión final recae en el rector Zolezzi. El Desconcierto. Recuperado de https://www.eldesconcierto.cl/2018/12/19/estudiantes-sumariadas-arriesgan-expulsion-tras-denunciar-casos-de-acoso-en-la-usach-rector-zolezzi-tomara-decision-final/

Jelil Ladebo, O. (2003). Sexual Harassment in Academia in Nigeria: How Real? African Sociological Review, 7 (1), 117-130.

Kelley, M. y Parsons, B. (2000). Sexual Harassment in the 1990s: A University-wide Survey of Female Faculty, Administrators, Staff, and Students. The Journal of Higher Education, 71 (5), 548-568.

Kihnley, J. (2000). Unraveling the Ivory Fabric: Institutional Obstacles to the Handling of Sexual Harassment Complaints. Law y Social Inquiry, 25 (1), 69-90.

La Izquierda Diario (16 de mayo de 2018). Red de Historiadoras feministas se pronuncia ante tomas y movilizaciones feministas. Recuperado de http://www. laizquierdadiario.com/Red-de-Historiadoras-feministas-se-pronuncia-ante-tomas-y-movilizaciones-feministas?id_rubrique $=1201$

La Tercera. (16 de mayo de 2018). ¿Y cómo anda el feminismo en la "cota mil"? U. de Los Andes, UDD, Finis Terrae y UAl marchan y se organizan. Recuperado de https://www.latercera.com/la-tercera-pm/noticia/los-andes-adolfo-ibanez-udd-finis-terrae-asi-sacudidas-las-universidades-cota-mil-feminis$\mathrm{mo} / 167322 /$

Lillo, D. (2020). Política, cuerpo y escuela: expresiones feministas en el marco del Movimiento Estudiantil Secundario 2011 -2016 en Chile. Debate Feminista, (59), 72-93.

Lorde, A. (2007). Sister Outsider. New York: Crossing Press.

Lykke, N. (2010). Feminist Studies. A Guide to Intersectional Theory, Methodology and Writing. New York: Routledge.

MacKinnon, C (1979). Sexual Harassment of Working Women: A Case of Sex Discrimination. New Haven: Yale University Press.

MINEDUC (2016). Protocolos contra el acoso sexual en Educación Superior: Sugerencias para su elaboración. Santiago: Ministerio de Educación. Recuperado de https://www.mineduc.cl/wp-content/uploads/sites/19/2017/09/Procoloscontra-el-acoso-sexual-en-ESUP.pdf

Montes, R. (4 de octubre de 2018). La gran ola que cambia Chile empezó en la universidad. El País. Recuperado de https://elpais.com/sociedad/2018/09/30/ 
actualidad/1538322187 839552.html

Muñoz, D. (23 de julio de 2018). Acoso sexual: investigan 132 casos en 16 universidades. La Tercera. Recuperado de https://www.latercera.com/nacional/ noticia/acoso-sexual-investigan-132-casos-16-universidades/252893/

Muñoz-García, A.L., Follegati, L. y Jackson, L. (Mayo 2018). Protocolos de acoso sexual en universidades chilenas: Una deuda pendiente. CEPPE Policy Briefs, (20), CEPPE UC.

Ortiz, J. (14 de noviembre de 2017). Acoso y abuso sexual en universidades: 228 denuncias fueron recepcionadas en 2016. Publimetro. Recuperado de https://www.publimetro.cl/cl/noticias/2017/1 1/14/acoso-abuso-sexual-universidades-228-casos-fueron-recepcionados-2016.html

Oyarce, N.; Leihy, P. y Zegers, J. (2020). Crisis de la Educación Superior en el Chile neoliberal: mercado y burocracia. Educar em Revista. Vol. 36 (e775369. Doi 10.1590/0104-4060.77536.

Paredes, J. P.; Araya, C. y Ortiz, N. (Enero de 2019). Primer Informe de Coyuntura de Conflictos Sociales: el Mayo Feminista 2018. Red Democratización y Movimientos Sociales. CEDER. Universidad de Los Lagos.

Paredes, J.P. (2019). De la Revolución Pinguina a la arena de la gratuidad. Balance de 10 años de luchas estudiantiles en Chile (2007-2017). En R. Díez y G. Betancor, G. (Eds.). Movimientos sociales, acción colectiva y cambio social en perspectiva (pp. 133-147). Abadiño, España: Fundación Betiko.

Red Chilena contra la Violencia hacia las Mujeres. (2016). Educación No Sexista. Hacia una Real Transformación. Santiago. Recuperado de http://www.nomasviolenciacontramujeres.cl/wp-content/uploads/2016/10/36621_RED-2016-WEB.pdf

Red de Investigadoras (8 de mayo de 2018). Redl impulsa creación de ley que sancione el acoso sexual en contextos educativos. Recuperado de https://redinvestigadoras.cl/2018/05/08/redi-impulsa-la-creacion-de-ley-que-sancione-el-acoso-sexual-en-contextos-educativos/

.(27 de diciembre de 2017). Declaración pública por sumario de acoso en la UACH por docente que ya tuvo uno el 2004. Recuperado de https://redinvestigadoras. cl/2017/12/27/declaracion-publica-por-sumario-de-acoso-en-la-uach-por-docente-que-ya-tuvo-uno-el-2004/

Reyes-Housholder, C. y Roque, B. (2019). Chile 2018: desafíos al poder de género desde la calle hasta La Moneda. Revista Ciencia Política (Santiago), Vol. 39 (2), 191 2015.

Richard, N. (2018). La insurgencia feminista de mayo 2018. En F. Zerán, F. (Ed). Mayo feminista. La rebelión contra el patriarcado (pp. 115-121). Santiago: LOM.

Rico, N. (1996). "Violencia de género: un problema de derechos humanos". CEPAL, Serie Mujer y Desarrollo, (16).

Rogel-Salazar, R. (2018). El grupo de discusión: revisión de premisas metodológicas Cinta Moebio, (Santiago), (63), 274-282. Recuperado de https://scielo.conicyt.cl/ $\mathrm{pdf} / \mathrm{cmoebio} / \mathrm{n63} / 0717-554 \mathrm{X}-\mathrm{cmoebio}-63-00274 . \mathrm{pdf}$

Robert, S., Pitzer, H., Munoz Garcia, A.L. (2018) Neoliberalism, Gender and Education Work. London: Routledge.

Salinas, F. (9 de mayo de 2019). Desvinculadas irregularmente por denunciar: El caso de dos ex académicas de la U. de O'Higgins. Radio La Clave. Recuperado de https://radiolaclave.cl/reportajes/desvinculadas-irregularmente-por-denunciar-el-caso-de-dos-ex-academicas-de-la-u-de-ohiggins/

T13 móvil. (30 de septiembre de 2020). Agresiones a mujeres: Alerta por alza de casos y el tipo de violencia ejercida durante la cuarentena. Recuperado de https:// www.t13.cl/noticia/nacional/agresiones-mujeres-alerta-alza-casos-y-tipo-violencia-ejercida-cuarentena-30-09-2020

Troncoso, L., Follegati, L., y Stutzin, V. (2019). Más allá de una educación no sexista: aportes de pedagogías feministas interseccionales. Pensamiento Educativo, 56 (1), 1-15.

Uggen, C. y Blackstone, A. (2004). Sexual Harassment as a Gendered Expression of Power. American Sociological Review, 69 (1), 64-92.

Varela Guinot, H. (2020). Las universidades frente a la violencia de género: el alcance limitado de los mecanismos formales. Revista Mexicana de Ciencias Políticas y Sociales. 65 (2389), 49-80. Doi 10.22201/fcpys.2448492xe.2020.238.68301

Vohlidalova, M. (2011). The Perception and Construction of Sexual Harassment by Czech University Students. Czech Sociological Review, 47 (6), $1119-1147$. 
Wessel, L. y Pérez, R. (24 de febrero de 2020). 'Se prendió la chispa': Científicas de Latinoamérica intensifican la lucha contra el acoso sexual. Science. Recuperado de https://www.sciencemag.org/news/2020/02/se-prendi-la-chispa-cient-ficasde-latinoam-rica-intensifican-la-lucha-contra-el-acoso

Welsh, S. (1999). Gender and Sexual Harassment. Annual Review of Sociology, (25), 169-190.

Williams, E., Lam, J. y Shively, M. (1992). The Impact of a University Policy on the Sexual Harassment of Female Students. The Journal of Higher Education, 63 (1), 50-64.

Yañez, D. y Salazar, M. (31 de marzo de 2016). Alumnas de la U. de Chile denuncian acoso de profesor de historia. The Clinic. Recuperado de https://www. theclinic. cl/2016/03/31/alumnas-de-la-u-de-chile-denuncian-acoso-de-profesor-de-historia/

Zapata, C. (20 de abril de 2016). Acoso sexual en las universidades: sobre Jaime Massardo Blanco. Red Chilena contra la Violencia hacia las Mujeres. Recuperado de http://www.nomasviolenciacontramujeres.cl/acoso-sexual-en-las-universidades/

Zerán, F. (Ed) (2018). Mayo feminista. La rebelión contra el patriarcado. Santiago: LOM.

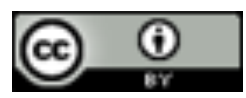

Este es un artículo de acceso abierto bajo licencia Creative Commons Reconocimiento 4.0 Internacional 